\title{
Debris flow mitigation with flexible ring net barriers - field tests and case studies
}

\author{
C. Wendeler ${ }^{1}$, B. W. McArdell ${ }^{1}$, A. Volkwein ${ }^{1}$, M. Denk ${ }^{2}$ \\ \& E. Gröner ${ }^{2}$ \\ ${ }^{1}$ WSL Swiss Federal Research Institute, Switzerland \\ ${ }^{2}$ Geobrugg AG Protection Systems, Switzerland
}

\begin{abstract}
A new type of debris flow mitigation measure, flexible ring-net barrier systems, are cost-effective and efficient compared to massive concrete barriers. However, the performance of these systems has not yet been investigated systematically. For this reason a wire ring-net barrier system has been installed in the Illgraben torrent, to investigate its performance, measure the forces and to provide information on the expected maintenance. Additionally, this net-testing facility allows for optimization of the structure and provides a basis for design guidelines. This paper describes the measurement facilities at the barrier and the debris flow events of 2006. First results of the filling event and their interpretation with the computational model are discussed.

Keywords: debris flow mitigation, flexible debris flow barriers, numerical simulation, field testing.
\end{abstract}

\section{Introduction}

Debris flows are initialised mostly by heavy rainfalls where the water quickly infiltrates into and mobilizes the ground material in mountainous regions. They flow downwards in riverbeds and along slopes, carrying large blocks and boulders, and endanger humans and their infrastructure. To reduce debris flow damage adequate protection measures have to be chosen. In regions where large debris flows occur frequently the best protection measures are typically large dams to re-route the debris to less vulnerable areas or special retention basins. But for smaller volumes a new protection system, the flexible ring-net barrier (Fig. 1), is now in a testing and developing phase in Switzerland. As shown here, 

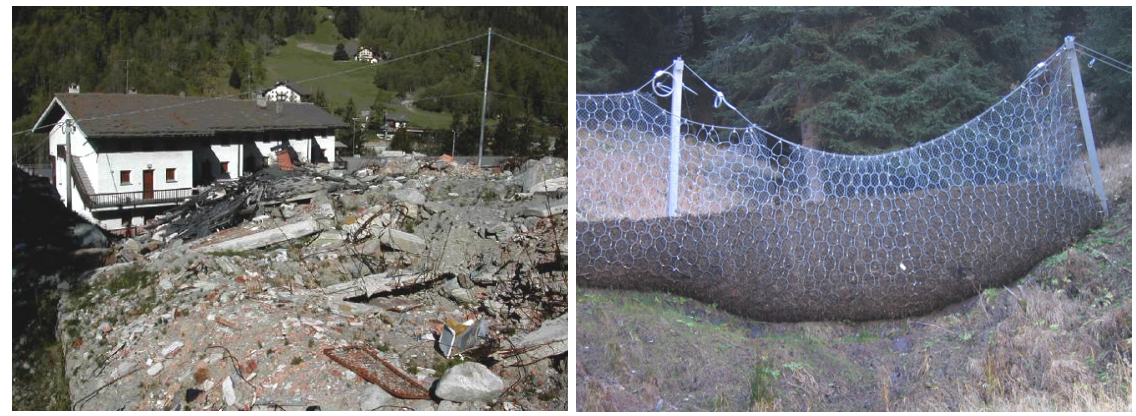

Figure 1: Debris flow deposit directly in front of a building and a filled flexible barrier system.

it can ideally be used to span the cross section of a river bed to stop the expected debris flow volume and to drain the material.

First tests with such ring-net barriers were carried out at the United States Geological Survey (USGS) Debris Flow Flume in 1996 [1] where the peak measured loads in the ropes were $40 \mathrm{kN}$ and $10 \mathrm{~m}^{3}$ of debris were retained. Motivated by these tests, the Swiss Federal Research Institute WSL built a fullscale test site in a very active debris flow channel in Switzerland.

One advantage of ring-net barriers in comparison to traditional concrete structures is that the ring-net barriers are light and flexible and can easily be installed in remote regions by transporting the system with helicopters. Furthermore, the maximum impact forces are reduced by long braking distances and flexible deforming structures. The stopping process has already been studied using similar barriers intended as protection against rockfall, woody debris in rivers or small snow slides. However, the load distribution over the barrier for debris flows is different than other applications. So, corresponding research is necessary, and a new project was initiated in 2005 that combines the results from full-scale field tests and laboratory experiments with numerical simulation results, giving new insight into the flow barrier interaction during and after a debris flow impact.

\section{Test site description}

In 2005, the first barrier system was installed at the Illgraben, one of the most active debris flow torrents in the Swiss Alps. The annual average debris flows occurring in the Illgraben lies between 4-6 events per season. Additionally, the torrent has been monitored by the WSL since 2000 and is equipped with geophones to measure the front travel time, laser, radar, and ultrasonic devices for the flow height, and a flow force plate to continuously record normal and shear forces, which together with the flow depth allows calculation of the bulk density of the flow [2]. 


\section{Barrier details}

There are two different set-ups of the barriers depending on the shape of the torrent (Fig. 2). For wide U-shaped channel cross sections, the so-called UBarrier system was developed with posts in the middle of the construction transferring the loads to the banks. For narrower V-shaped channels up to 12-15 $\mathrm{m}$ wide a so-called V-Barrier without any posts is sufficient. The standard construction height of these barriers is around 3-6 m.

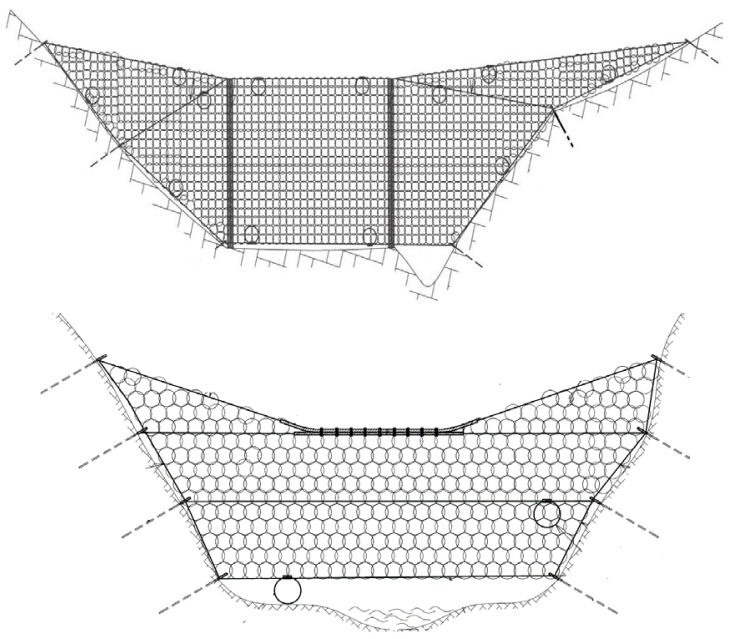

Figure 2: $\quad \mathrm{U}$ (top) and V-barrier system (bottom) against debris flow.

In both systems, a wire ring-net is mounted between the horizontal steel wire ropes that are anchored in both sides of the channel side slopes. Its function is to transport the area loads to the ropes where a part of the energy is absorbed by elongation of the so-called brake rings (see Fig. 3) installed in the ropes as a peak-force damping system. Loads up to $400 \mathrm{kN}$ can be carried and transferred to the anchors.

The test barrier system (Fig. 4) has been instrumented to measure the interaction of the flow with the barrier. Above the barrier, a laser device measures the flow height. On the right channel bank a video camera documents the debris flow events and their interaction with the barrier. At night, a flood light on the left channel side produces the additional illumination. To measure tension forces in the support ropes, load cells with a range up to $500 \mathrm{kN}$ are installed at the ends of the ropes. The system is triggered by a geophone installed upstream. The data are transferred to the WSL via a wireless data modem.

A newly designed test barrier was installed in late April 2006 in the torrent within a one week period (including earthworks to prepare the river bed at the barrier location) before the start of the debris flow season to avoid construction interruptions due to debris flows. The main difference to the barrier system of 2005 [3] is a change within the net panel from two support ropes and additional brake elements installed between the ring net and lateral anchors. 

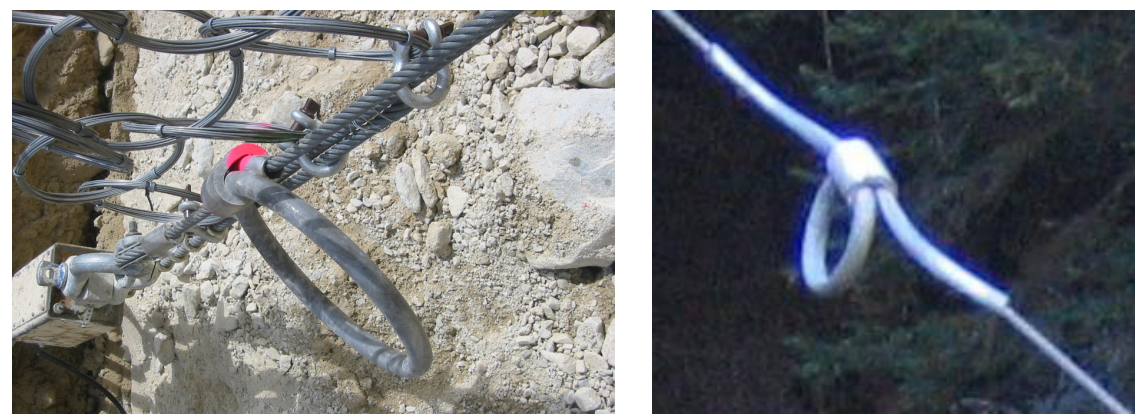

Figure 3: A not deformed brake ring (left) compared with an elongated one (right) installed in support ropes: A rope passes through a hollow steel tube bent into a ring form. Once the rope is loaded, the ring diameter narrows plastically thereby absorbing energy.

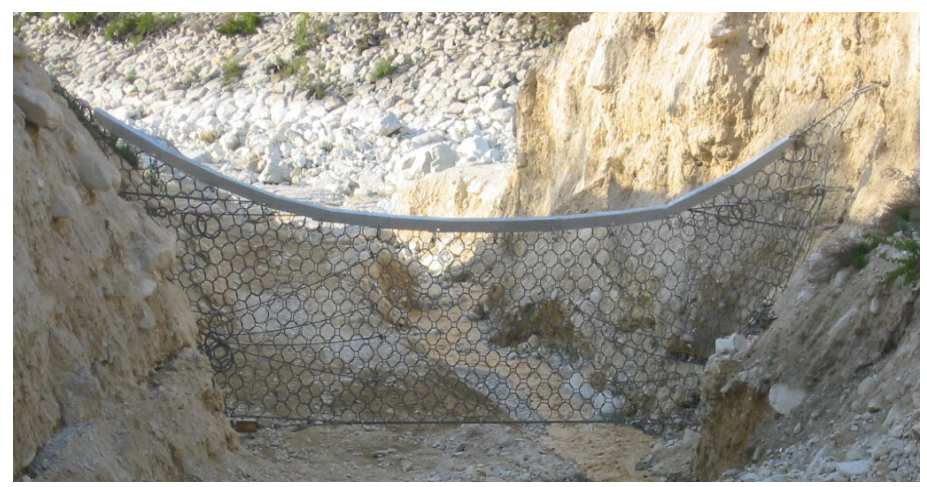

Figure 4: $\quad$ Construction phase and final set up of the barrier 2006.

\section{Field results}

Four weeks after installation, on May 18, the barrier captured the front of a debris flow and - after filling - was overtopped by subsequent flows, providing a chance to evaluate the behaviour under severe field conditions. Another five debris flows passed over the barrier during 2006 (Table 1). The two events in June were the largest ones by the total flow volume but considering the densities, the more powerful events were the events on July 28, and the one in October with densities larger than $2000 \mathrm{~kg} / \mathrm{m}^{3}$. The retained debris volume is $1000 \mathrm{~m}^{3}$, calculated from survey measurements, before and after the filling event (Fig. 5). The filling event itself, with a velocity of $2.9 \mathrm{~m} / \mathrm{s}$ and a bulk density value of about $1600 \mathrm{~kg} / \mathrm{m}^{3}$, was a muddy or watery debris flow. The low density of the filling debris flow partially explains the longer than normal filling time (more than 1 minute). The interaction with the barrier therefore was not as intense as it would have been for a granular debris flow, which typically occurs over a few seconds. 
Table 1: $\quad$ Overview of the debris flow events in 2006 at the Illgraben [6].

\begin{tabular}{|c|c|c|c|c|c|}
\hline \multirow[t]{2}{*}{ Date } & Volume & Density & $\begin{array}{l}\text { Flow } \\
\text { height }\end{array}$ & $\begin{array}{l}\text { Front } \\
\text { velocity }\end{array}$ & \multirow[t]{2}{*}{ Front shape } \\
\hline & $\mathrm{m}^{3}$ & $\mathrm{~kg} / \mathrm{m}^{3}$ & $\mathrm{~m}$ & $\mathrm{~m} / \mathrm{s}$ & \\
\hline 18 May & 15,000 & 1620 & 1.4 & 2.9 & Watery \\
\hline 24 June & 50,000 & $\begin{array}{l}1520 \\
1320\end{array}$ & 3.2 & 4.8 & $\begin{array}{l}\text { Granular } \\
\text { Watery }\end{array}$ \\
\hline 27 June & 70,000 & $(\sim 1800)$ & 2.5 & 3.9 & (granular body) \\
\hline 18 July & 50,000 & 1600 & 2.5 & 4.8 & Watery \\
\hline 28 July & 10,000 & 2130 & 1.4 & 2.0 & Granular \\
\hline 3 October & 10,000 & 2060 & 1.4 & 1.65 & Granular \\
\hline
\end{tabular}

Figure 5: $\quad$ Measured profile of the Illgraben torrent close to the test barrier before and after the filling event.

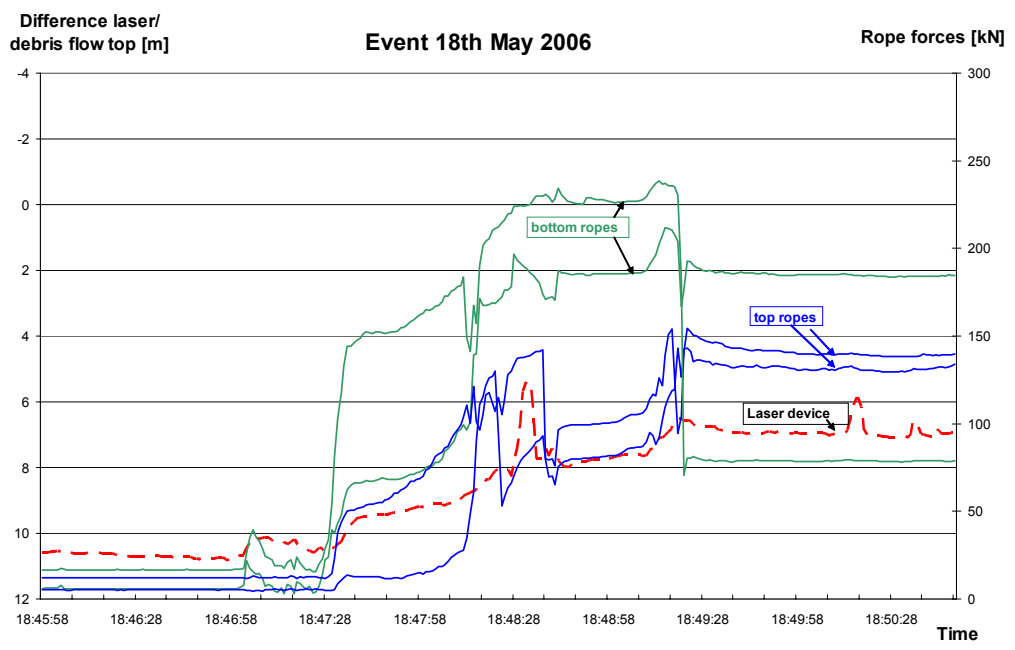

Figure 6: Tension forces in the load cells on May 18, 2006. 
The tension forces in the support ropes during the filling event are shown in Fig. 6. The maximum load level of the bottom support ropes is around $240 \mathrm{kN}$ each during the filling process. The top support ropes were loaded less, at 150 $\mathrm{kN}$ each. These values add to the existing data obtained earlier in field and laboratory tests $[1,3,4]$. This collection enables comparison and analysis [5].

\section{Discussion}

Ropes forces: One important observation of the filling process was that the bottom ropes are more loaded than the top ropes. The opening of the barrier at the river bed was around half a meter in height and so that small floods may pass beneath the barrier. During the subsequent overtopping phase it is reversed: then the top support ropes are directly influenced by the overflowing debris flow and are loaded more than the bottom support ropes. In every load curve of support ropes in Fig. 6, sudden losses of the rope forces are visible. This is caused by the elongation of the brake rings.

Load model: First guidelines for design of these flexible barrier systems are given in [7] based on an empirical design method by [8]. These formulas, based on conservation of energy, calculate the stopped volume and the discharge of the flow and work fine for granular flows. However, the filling process for mudflow streams (as on May $18^{\text {th }}$ ) isn't adequately modelled. Therefore a new calculation method has to be developed.

A first approach assumes that a muddy debris flow has a flow regime similar to a turbulent flood water event. Therefore, more the passing of the liquid phase and only some bigger boulders impacting the net comprise the load, compared to a dynamic impact of a larger-density debris flow filling up the barrier very rapidly. The pressure exerted on obstacles by a turbulent muddy debris flow then depends on flow velocity and the obstacle's front area and shape.

An overview of the calculated pressures is given in Table 2. The static pressure is calculated as active earth pressure based on Coulomb [9] with a density of the debris deposited behind the barrier of $2300 \mathrm{~kg} / \mathrm{m}^{3}$ and an inertial friction angle of $35^{\circ}$. Estimates for the basal friction angle can be found in McArdell et al. [2]. The table shows that the method explained in [7] results in a very high maximum dynamic pressure resulting due to the long filling time. In the second row the dynamic pressure is back-calculated iteratively from the measured rope forces using a Newton iteration according to a simplified rope analysis for uniform distributed loads. The resulting dynamic pressure is around $60 \mathrm{kN} / \mathrm{m}^{2}$. Similar magnitude estimates by the calculation of the dynamic pressure using a dynamic overload factor of $\mathrm{P}_{\text {dyn }} / \mathrm{P}_{\text {stat }}=2.2$ obtained from corresponding laboratory tests [10] shown in the third row. Ongoing additional resistance measurements of a ring-net in a clear water flow (no sediments) will help to consolidate the last two approaches and identify a lower boundary for the load level. The comparison with different debris flow measurements including solid structural concrete measures will be considered [5].

Numerical modelling: Once a model for the acting pressure has been found the results can be used in a corresponding numerical simulation tool that enables 
development of further barriers. The simulations are carried out with the finite element software FARO [11] based on a discrete element formulation. The software has been developed for the calculation of flexible rock fall barriers where the dynamic acting force of the impacting boulder induces large deformation in the entire system necessitating non-linear simulation methods. The software now has been modified to also account for forces induces by a debris flow. Figure 7 shows a simulated barrier together with the filled Illgraben barrier for an applied acting pressure according to Rickenmann [8]. The forces were applied quasi-statically.

Table 2: $\quad$ Pressure values on the barrier.

\begin{tabular}{llllll}
\hline & Velocity & $\begin{array}{l}\text { Velocity } \\
\text { head }\end{array}$ & $\begin{array}{l}\text { Obstacle } \\
\text { area }\end{array}$ & $\begin{array}{l}\text { Static } \\
\text { pressure }\end{array}$ & $\begin{array}{l}\text { Max. } \\
\text { pressure }\end{array}$ \\
\cline { 2 - 6 } & $\mathrm{m} / \mathrm{s}$ & $\mathrm{kg} / \mathrm{ms}^{2}$ & $\mathrm{~m}^{2}$ & $\mathrm{kN} / \mathrm{m}^{2}$ & $\mathrm{kN} / \mathrm{m}^{2}$ \\
\hline $\begin{array}{l}\text { Energy } \\
\text { conservation [8] }\end{array}$ & 2.9 & 6730 & 10.1 & 21.7 & 780.0 \\
$\begin{array}{l}\text { Back calculated } \\
\text { from measured } \\
\text { rope forces }\end{array}$ & 2.9 & 6730 & 10.1 & 21.7 & 59.4 \\
$\begin{array}{l}\text { Dynamic } \\
\text { factor =2.2 from } \\
\text { laboratory tests }\end{array}$ & 2.9 & 6730 & 10.1 & 21.7 & 47.8 \\
\hline
\end{tabular}

Table 3: $\quad$ Comparison of simulation results with measured field data.

\begin{tabular}{llll}
\hline \multirow{2}{*}{ Support ropes } & Simulated forces & $\begin{array}{l}\text { Measured field } \\
\text { forces }\end{array}$ & Deviation \\
\cline { 2 - 4 } & $\mathrm{kN}$ & $\mathrm{kN}$ & $\%$ \\
\hline Top & 160 & 150 & 6 \\
Bottom & 210 & 248 & 15 \\
\hline
\end{tabular}
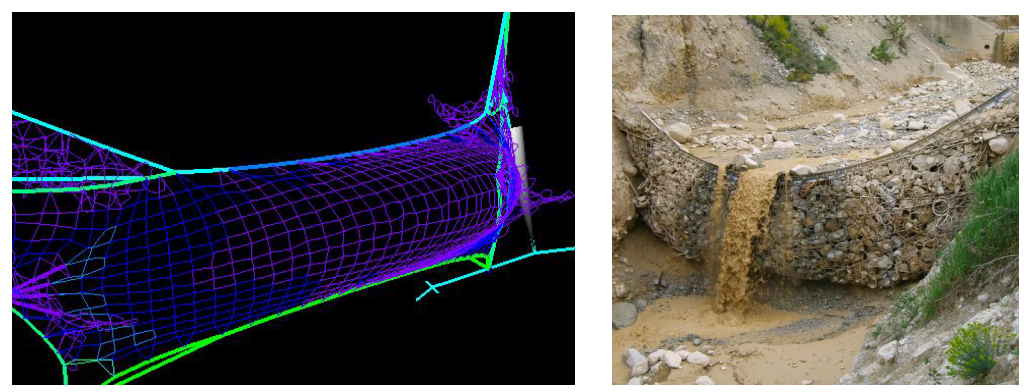

Figure 7: Finite element model of the test barrier compared to the deformed field barrier.

Both the forces in the ropes (Table 3) and the deformations correspond well to the field observations. The actual load application first calculates the mass to be 
stopped and the resulting total kinetic energy that has to be absorbed using the energy conservation approach described above. Together with an estimated braking distance this results in a total brake force that is equally distributed on the single element nodes of the finite element model. The node loads increase over the time as the barrier is progressively filled.

\section{Case study}

Multilevel debris flow barrier Milibach, Hasliberg, Bernese Oberland / Switzerland

Floods and a debris flow event occurred in the Milibach on 22. August 2005 which resulted in serious debris coverage and damage in the Weiler Reuti / Hasliberg and in Meiringen. The Milibach above Reuti comprises two part creeks, the Lauenenbach being situated in the upper catchment area in the Alenienschiefer (schist). Due to heavy rainfalls, within about 1 hour a total of approximately $13^{\prime} 000 \mathrm{~m}^{3}$ of loose soil material became detached and flowed downhill as a mudflow in 2 to 3 surges (muddy debris flow, rich in fine material).

On the way to the valley, additional soil material was eroded from the riverlet, resulting in a much greater event in Meiringen than the original volume.

For the upper drainage area of the Lauenenbach ("Gummen"), provision has been made for the debris flow to be held back during a future event (return period 30 years) by means of 13 flexible, debris flow barrier systems installed in series (Fig. 8). These are arranged and dimensioned to provide sufficient retention volumes and are also capable of bearing the expected debris flow impact and overflow loads, as well as snow and static loads.
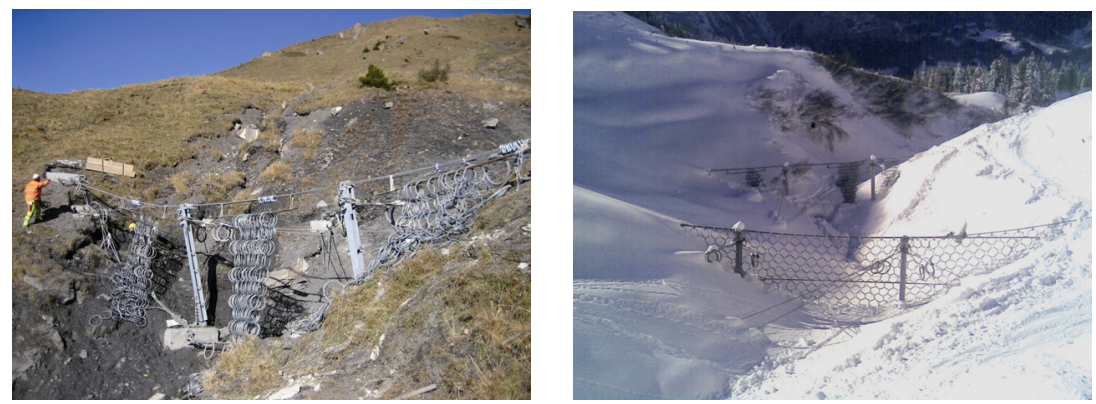

Figure 8: $\quad$ Barrier under construction at Gummen (left). Two barriers already installed (right).

\section{Conclusion}

The Illgraben torrent observation station is ideal to test flexible net barriers under natural conditions due to the relatively frequent occurrence of large debris flows. First testing phases 2005 and 2006 revealed good results to help in the proper design and improvement of these systems. An improved barrier set up will be 
installed in spring 2007 to further optimise the design. First load approaches and back calculations already show promising results for further developments.

\section{Acknowledgements}

We thank Bruno Fritschi for his careful and competent design of the Illgraben observation station and instrumentation for the barrier. We are grateful to Francois Dufour, Alexandre Badoux, and Christoph Graf for their daily support within this project.

\section{References}

[1] DeNatale, J. S., Iverson, R. M., Major, J. J., LaHusen R.G., Fliegel, G. L., Duffy, J. D. 1999. Experimental Testing of flexible barriers for containment of debris flows, Open-File Report 99-205, U.S. Geological Survey.

[2] McArdell, B. W., Bartelt, P. \& Kowalski, J. 2007. Field observations of basal forces and fluid pore pressure in a debris flow. Geophysical Research Letters, 34 (LO7406), doi:10.1029/2006GL029183.

[3] Wendeler, C., McArdell, B. W., Rickenmann, D., Volkwein, A., Roth, A., Denk, M. 2006. Field testing and numerical modelling of flexible debris flow barriers, Proc. Int. Conf. on Physical Modelling in Geotechnics, Hong Kong.

[4] DeNatale, J. S., Fiegel, G. L., Iverson R. M., Major J. J., LaHusen, R. G., Duffy, J.D. \& Fisher, G. D.. 1997. Response of flexible wire rope barriers to debris flows loading. Proc. $1^{\text {st }}$.International Conference on DFHM, ASCE, San Francisco, pp 616-625.

[5] Wendeler, C. In preparation. Field investigations and modeling of the interaction of debris flows with flexible ring-net barriers. Doctoral dissertation, ETH Zurich, Switzerland.

[6] McArdell, B. W., Wendeler, C., Roth, A., Kalejta, J., Rorem, E. 2007. Field observations of the interaction of debris flows with flexible barriers, First North American Landslide Conference, Vail.

[7] Roth, A., Kästli, A. \& Frenez, Th. 2004. Debris Flow Mitigation by Means of Flexible Barriers, Proc. Int. Symp. Interpraevent. Riva del Garda, Italy. Klagenfurt: Interpraevent.

[8] Rickenmann, D. 1999. Empirical relationships for debris flows. Natural Hazards. 19(1): 47-77.

[9] Gudehus, G. 1981. Bodenmechanik. Ferdinant Enke Verlag, Stuttgart.

[10] Wendeler C., B.W. McArdell, D. Rickenmann, A. Volkwein, A. Roth \& M. Denk. 2005. Testing and numerical modeling of flexible debris flow barriers, in Ng, Zhang \& Wang (Eds), Physical Modeling in Geotechnics $6^{\text {th }}$ ICPMG '06, Balkema.

[11] Volkwein A. 2005. Numerical Simulation of flexible rockfall protection systems, Proc. Computing in Civil Engineering. Cancun: ASCE. 